Synthesis and Evaluation of $\left[{ }^{18}\right.$ F]RAGER: A First Generation Small-Molecule PET

Radioligand Targeting the Receptor for Advanced Glycation Endproducts

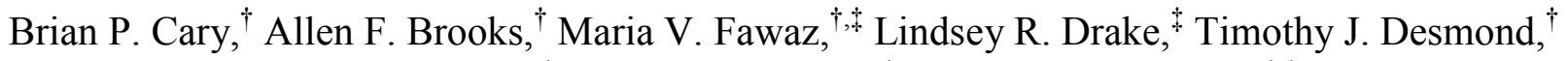
Phillip Sherman, ${ }^{\dagger}$ Carole A. Quesada ${ }^{\dagger}$ and Peter J. H. Scott $*, \dagger, \dagger$

${ }^{\dagger}$ Division of Nuclear Medicine, Department of Radiology, University of Michigan Medical School, Ann Arbor, MI, USA

\# The Interdepartmental Program in Medicinal Chemistry, The University of Michigan, Ann Arbor, MI, USA

*pjhscott@umich.edu

Table of Contents:

I. Chemistry and Characterization $\quad$ S2

$\begin{array}{ll}\text { II. Radiochemistry } & \text { S11 }\end{array}$

$\begin{array}{ll}\text { III. Immunohistochemistry } & \text { S13 }\end{array}$

$\begin{array}{ll}\text { IV. Autoradiography } & \text { S14 }\end{array}$

$\begin{array}{ll}\text { V. LogP Determination } & \text { S14 }\end{array}$

$\begin{array}{ll}\text { VI. Rodent and Primate MicroPET } & \text { S15 }\end{array}$

$\begin{array}{ll}\text { VII. Molecular Docking } & \text { S16 }\end{array}$

$\begin{array}{ll}\text { VIII. Liver Microsome Metabolism Study } & \text { S18 }\end{array}$

$\begin{array}{ll}\text { IX. References } & \text { S21 }\end{array}$ 


\section{Chemistry and Characterization}

General Considerations: All solvents and reagents were commercially available and used without further purification unless otherwise stated. Cyclohexylamine was purchased from Acros Organics. Benzaldehyde, 4-fluorobenzoyl chloride and 4-( $N, N$-dimethyl)benzoyl chloride were purchased from Sigma Aldrich. NMR spectra were recorded with a Varian $400 \mathrm{MHz}$ instrument at room temperature (unless otherwise specified) with tetramethylsilane (TMS) as an internal standard. ${ }^{1} \mathrm{H},{ }^{13} \mathrm{C}$, and ${ }^{19} \mathrm{~F}$ spectra were recorded at $400 \mathrm{MHz}, 100 \mathrm{MHz}$, and $376.3 \mathrm{MHz}$, respectively. Mass spectra were performed on an Agilent Q-TOF HPLC-MS or a Micromass LCT time-of-flight mass spectrometer, employing the electrospray ionization (ESI) method. High performance liquid chromatography (HPLC) was performed using a Shimadzu LC-2010A HT system equipped with a Bioscan B-FC-1000 radiation detector. All procedures including anhydrous solvents were performed using Schlenk techniques with rigorously dried glassware. 


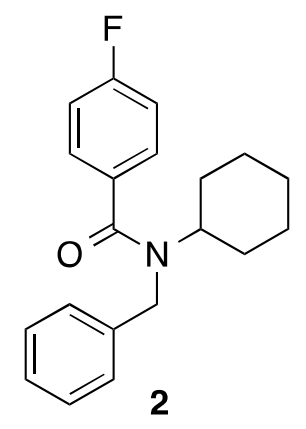

Preparation of N-benzyl-N-cyclohexyl-4-fluorobenzamide (2): see main manuscript.

${ }^{1} \mathrm{H}-\mathrm{NMR}$ of (2)

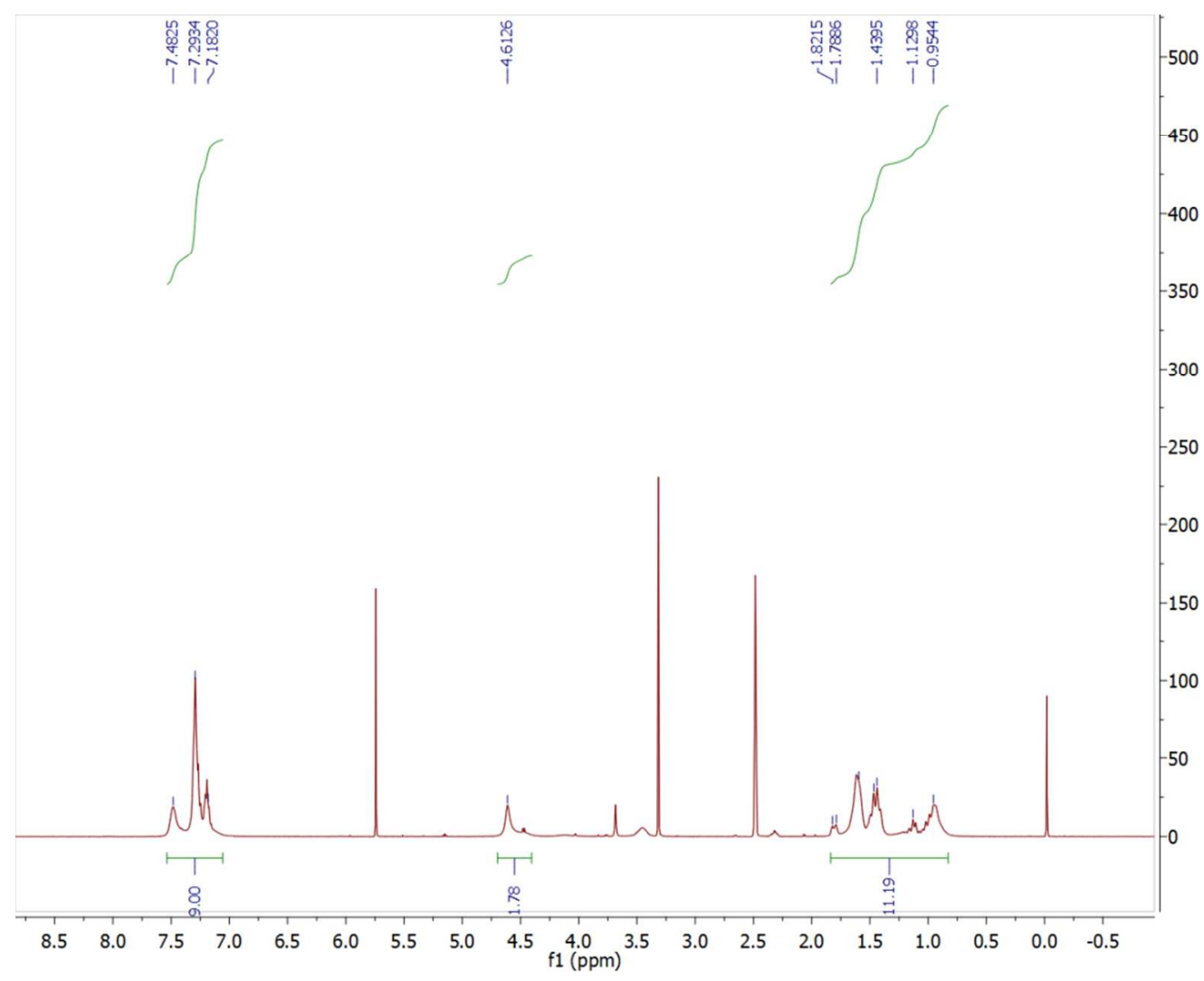


${ }^{13} \mathrm{C}-\mathrm{NMR}$ of (2)

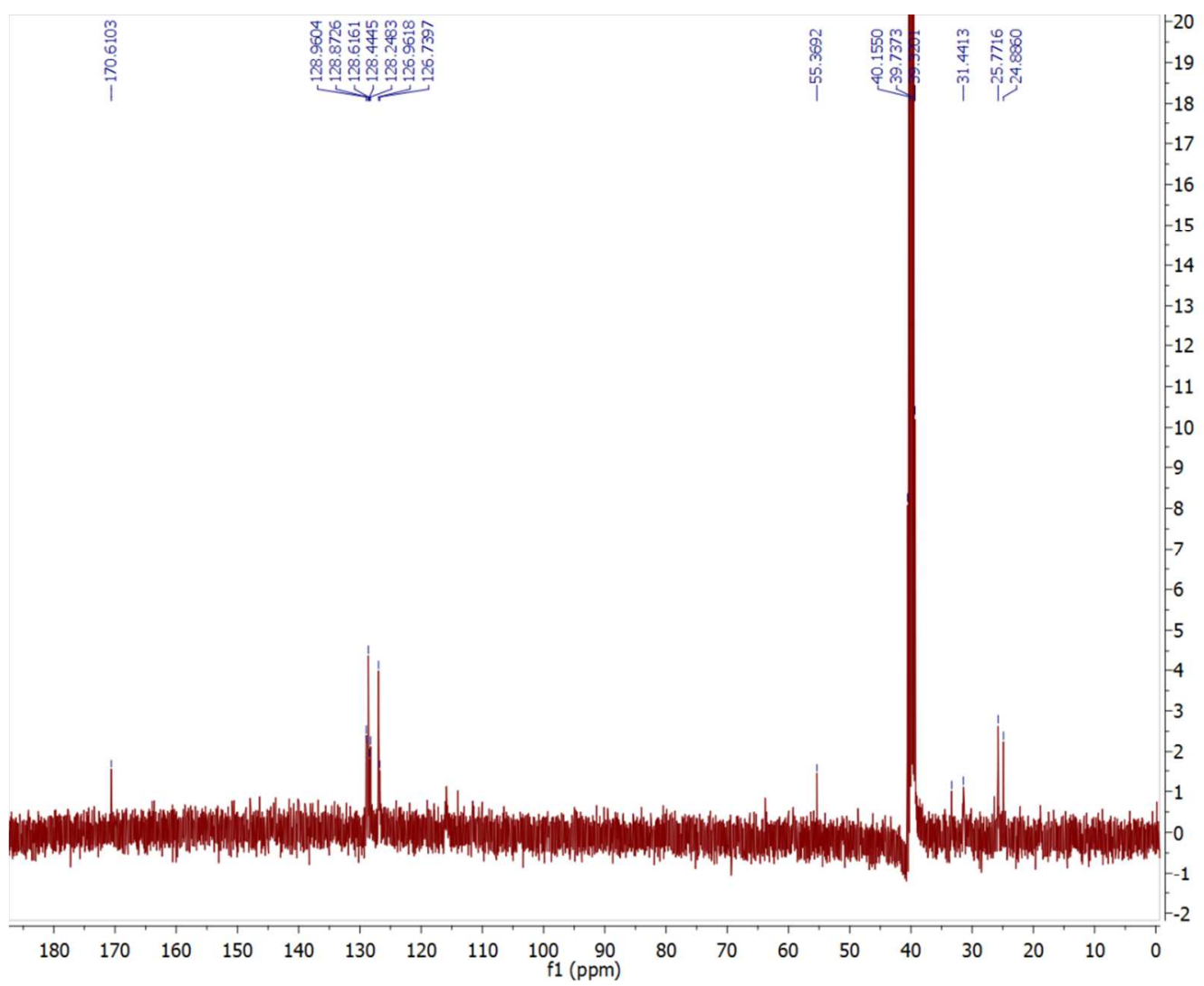


${ }^{19}$ F-NMR of (2)

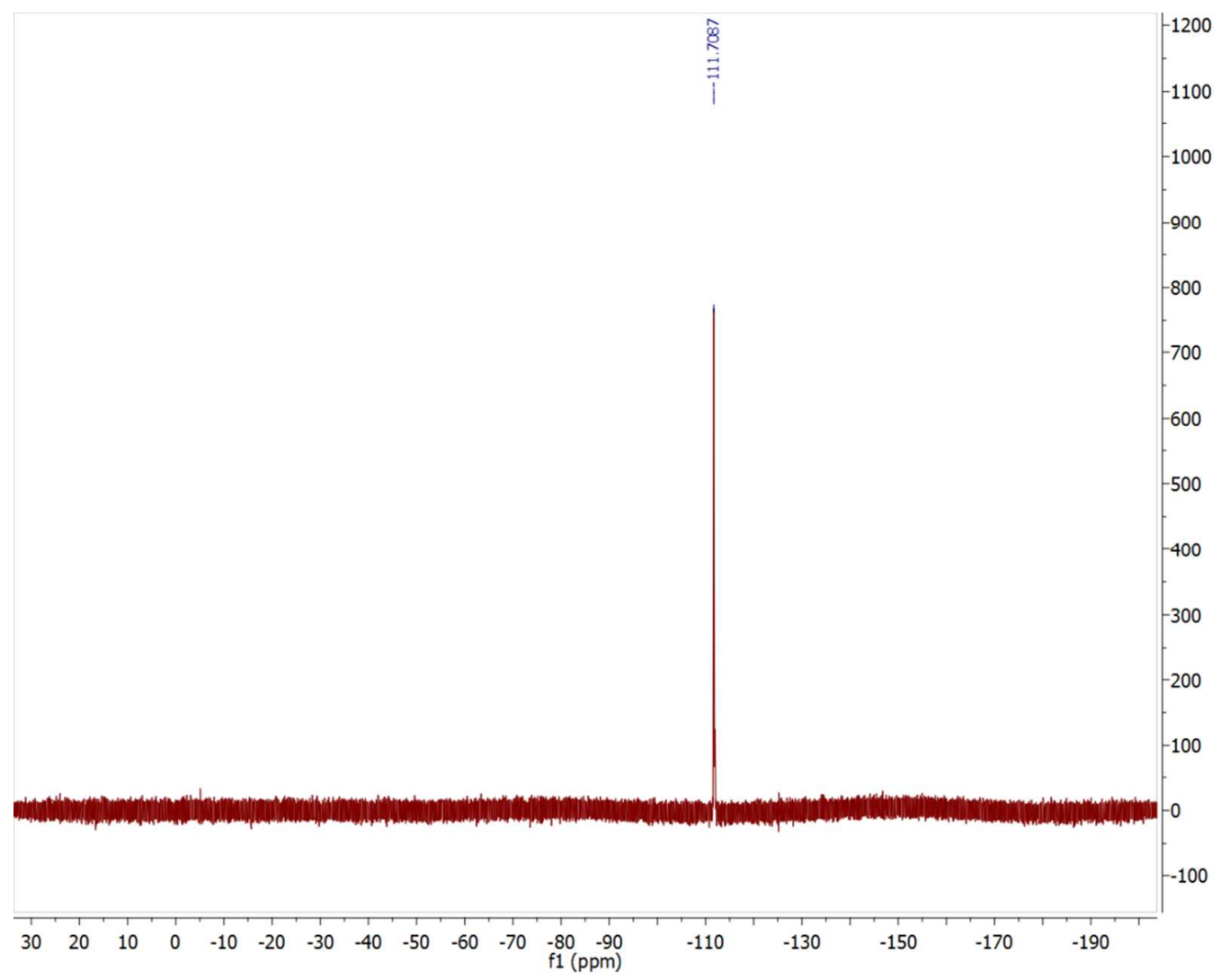

HRMS of (2)

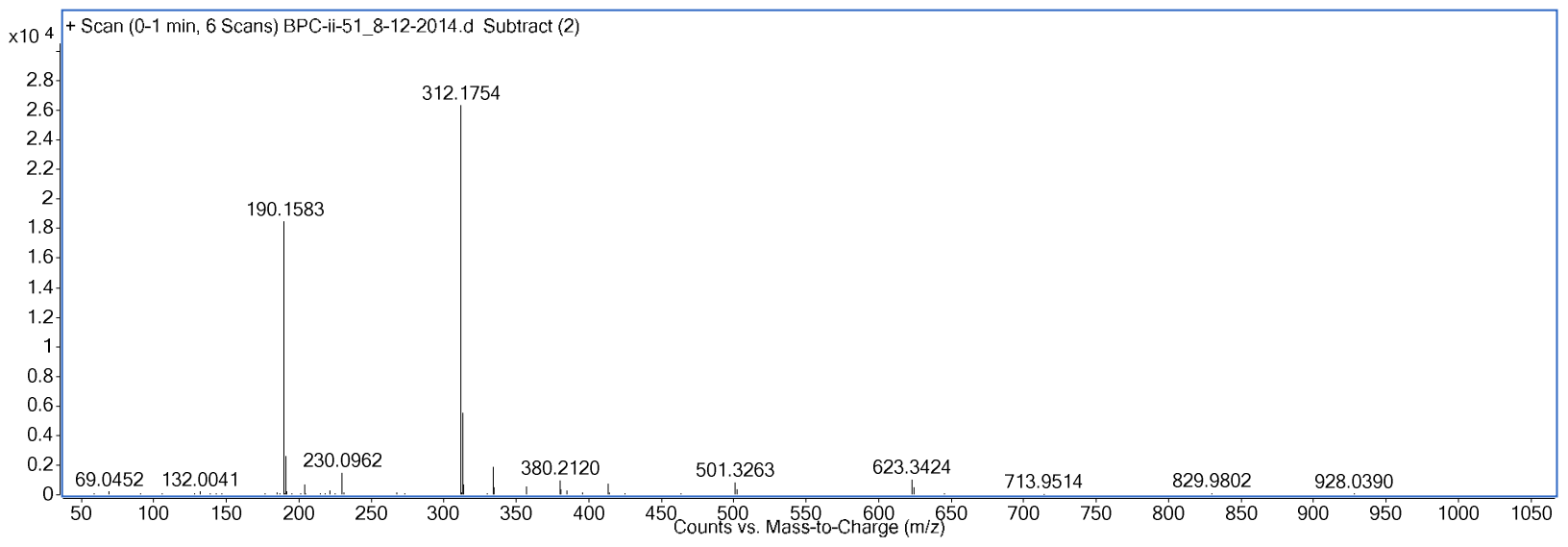


HPLC of (2)

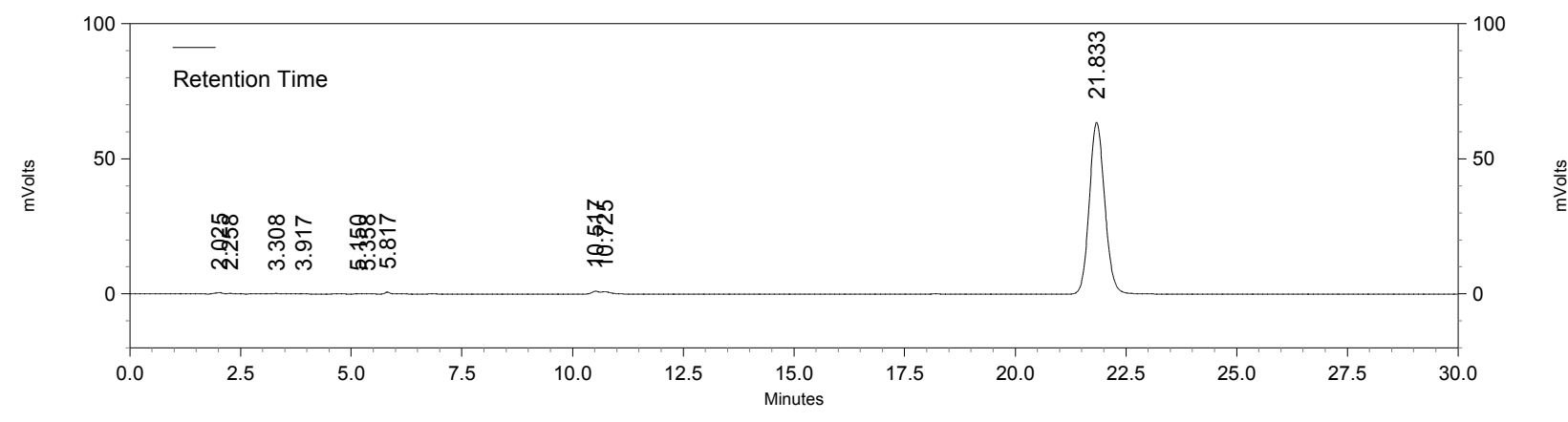

\begin{tabular}{|c|c|c|c|c|c|}
\hline $\begin{array}{l}\text { UV Detector } \\
\text { Ch1-254nm } \\
\text { Results }\end{array}$ & & & & & \\
\hline $\begin{array}{l}\text { Retention } \\
\text { Time }\end{array}$ & Area & Area $\%$ & Height & Width & $\begin{array}{c}\text { S/N } \\
(\mathrm{ASTM})\end{array}$ \\
\hline 21.833 & 1533265 & 98 & 63589 & 1.708 & 6650.55 \\
\hline
\end{tabular}




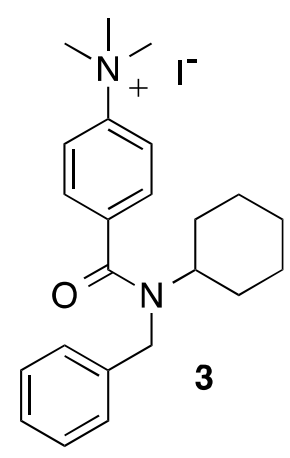

Preparation of 4-(benzyl(cyclohexyl)carbamoyl)- $N, N, N$-trimethylbenzenaminium iodide (3): see main manuscript.

${ }^{1} \mathrm{H}-\mathrm{NMR}$ of (3)

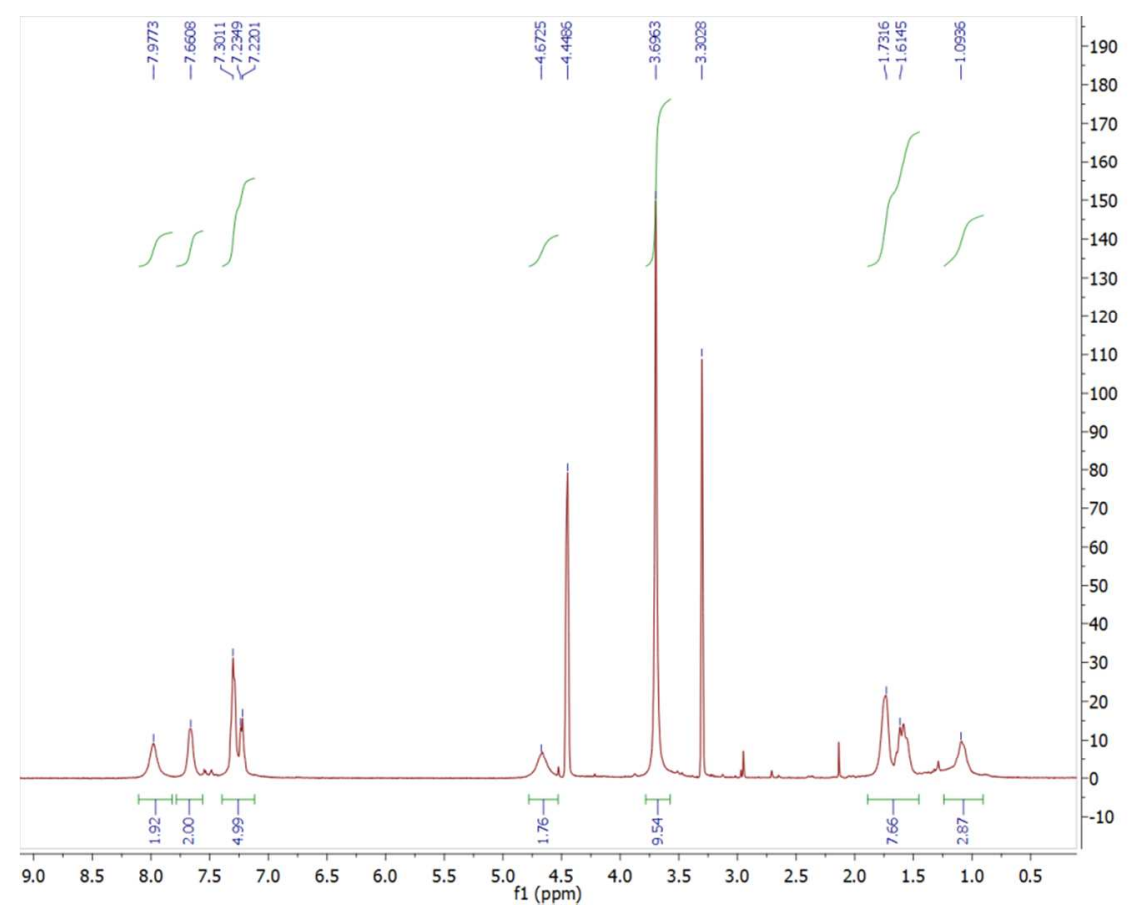


${ }^{13} \mathrm{C}-\mathrm{NMR}$ of (3)

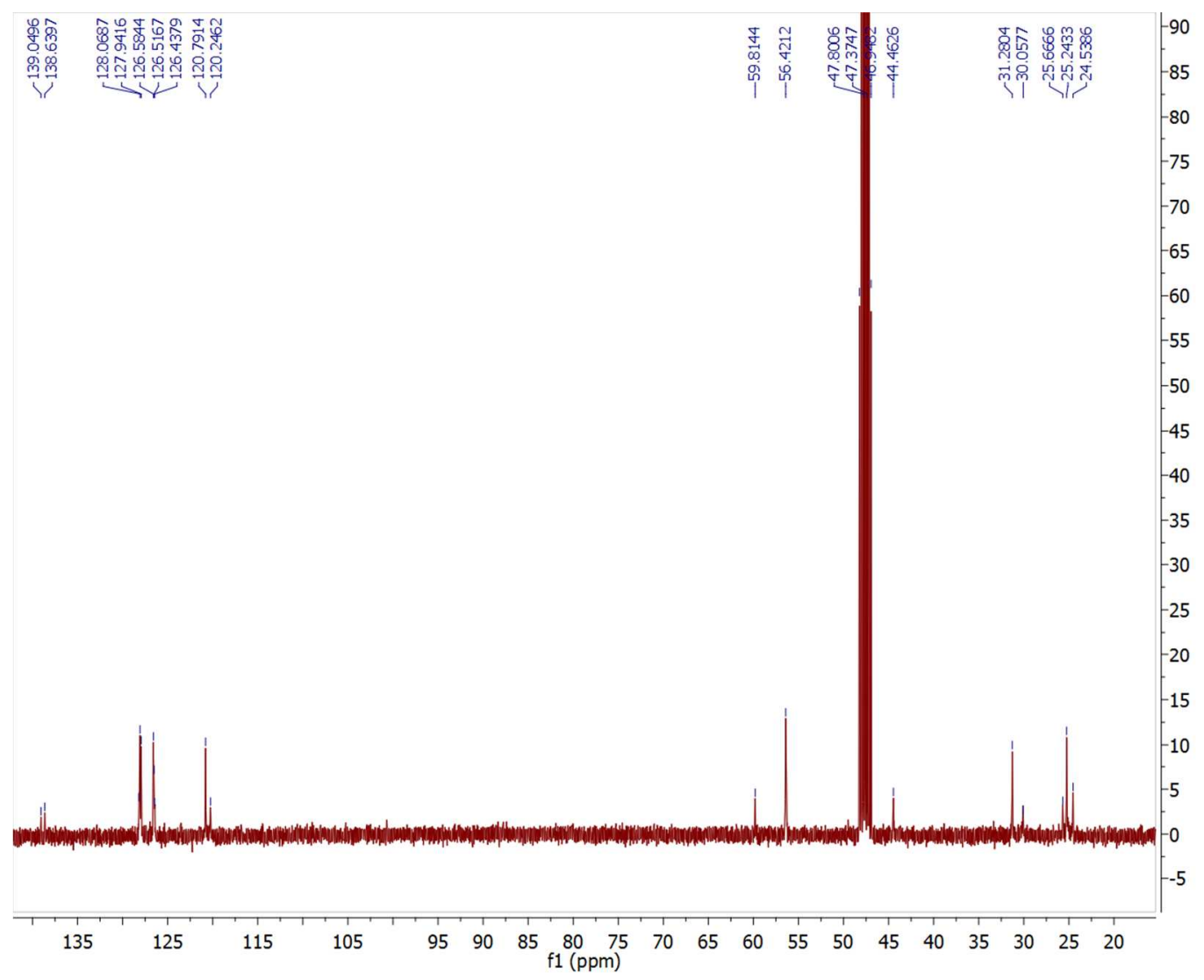

HRMS of (3)

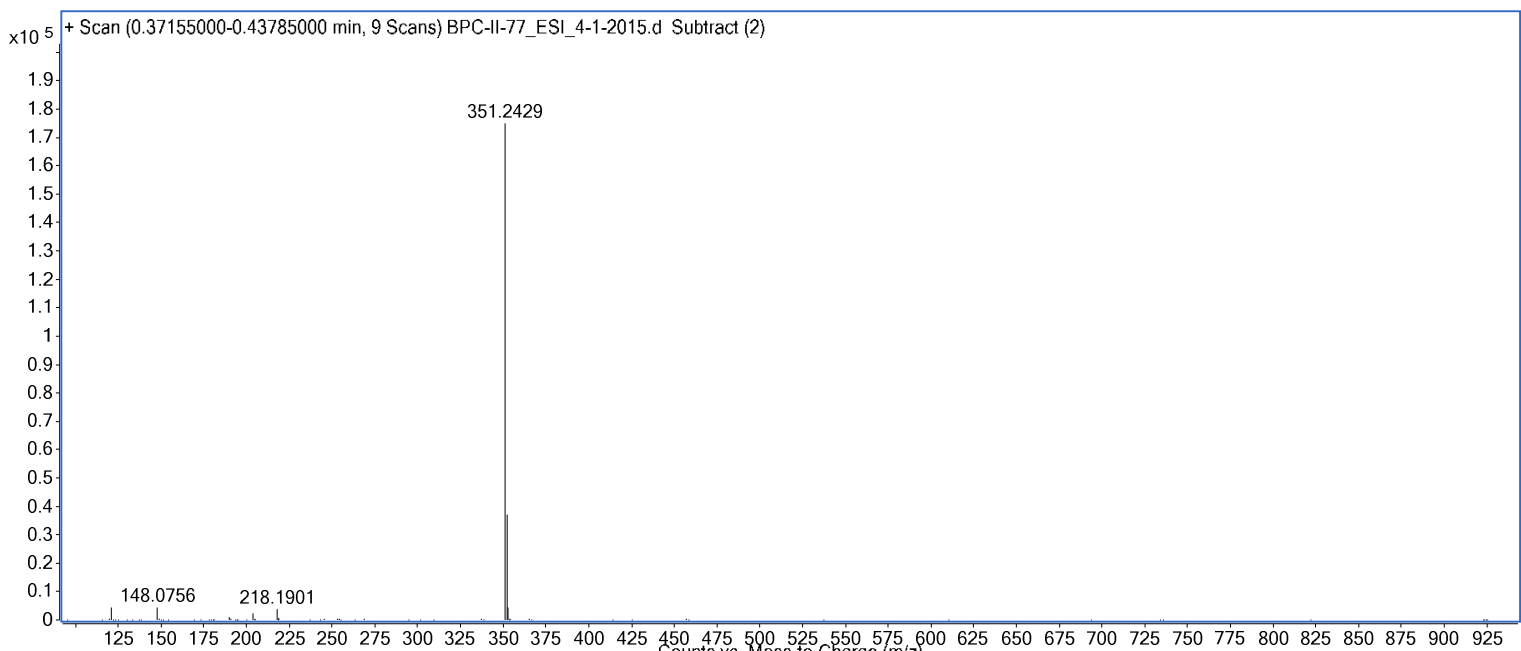




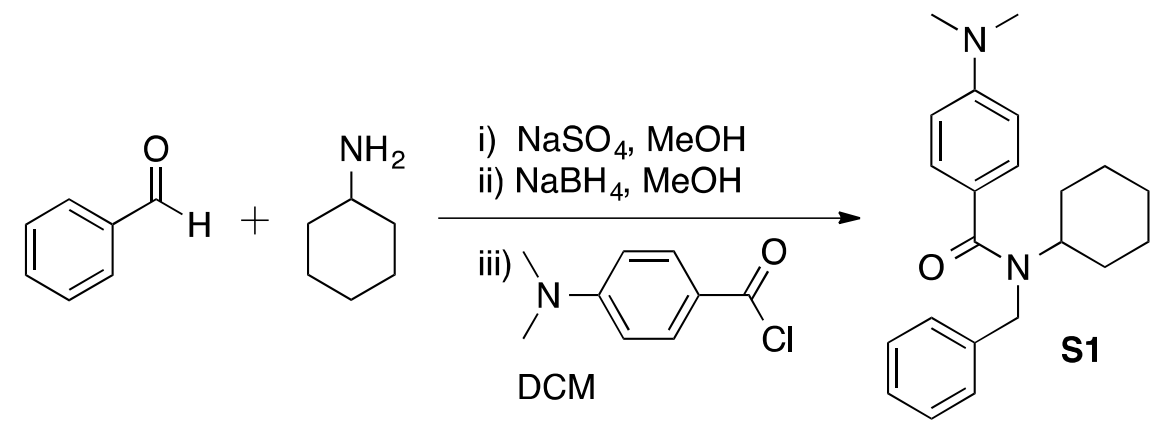

Preparation of N-benzyl-N-cyclohexyl-4-(dimethylamino)benzamide (S1): Procedure followed the same protocol for the synthesis of $\mathbf{2}$ (see main manuscript), but instead utilized 4(dimethylamino)benzoyl chloride $(349 \mathrm{mg}, 1.90 \mathrm{mmol}$ ) and a partition of the crude $\mathrm{N}$ benzylcyclohexanamine intermediate $(300 \mathrm{mg}, 1.58 \mathrm{mmol})$. This process yielded a white solid (71.8 mg, $0.213 \mathrm{mmol}, 13.5 \%)$; $\mathrm{R}_{\mathrm{f}}$ : $0.63\left(\mathrm{SiO}_{2}, 1: 1=\right.$ hexanes: ethyl acetate); ${ }^{1} \mathrm{H}$ NMR (400 MHz; $\left.\mathrm{CDCl}_{3}\right) / \delta(\mathrm{ppm}): 0.96-1.26(4 \mathrm{H}, \mathrm{m}), 1.43-1.76(8 \mathrm{H}, \mathrm{m}), 2.98(6 \mathrm{H}, \mathrm{s}), 4.65(2 \mathrm{H}, \mathrm{s}), 6.66(2 \mathrm{H}, \mathrm{d}, J=$ $8.3 \mathrm{~Hz}), 7.20-7.31(6 \mathrm{H}, \mathrm{m}), 7.38(2 \mathrm{H}, \mathrm{d}, J=8.7 \mathrm{~Hz}) ;{ }^{13} \mathrm{C} \mathrm{NMR}\left(100 \mathrm{MHz} ; \mathrm{CDCl}_{3}\right) / \delta(\mathrm{ppm}):$ 24.97, 25.36, 25.85, 31.66, 40.24, 111.34, 124.28, 126.53, 126.88, 128.23, 139.87, 151.17, 172.79; HRMS: calculated for $[\mathrm{M}+\mathrm{H}]^{+}\left(\mathrm{M}=\mathrm{C}_{22} \mathrm{H}_{28} \mathrm{~N}_{2} \mathrm{O}\right), 337.2274$, found 337.2273.

\section{${ }^{1} \mathrm{H}-\mathrm{NMR}$ of (S1)}

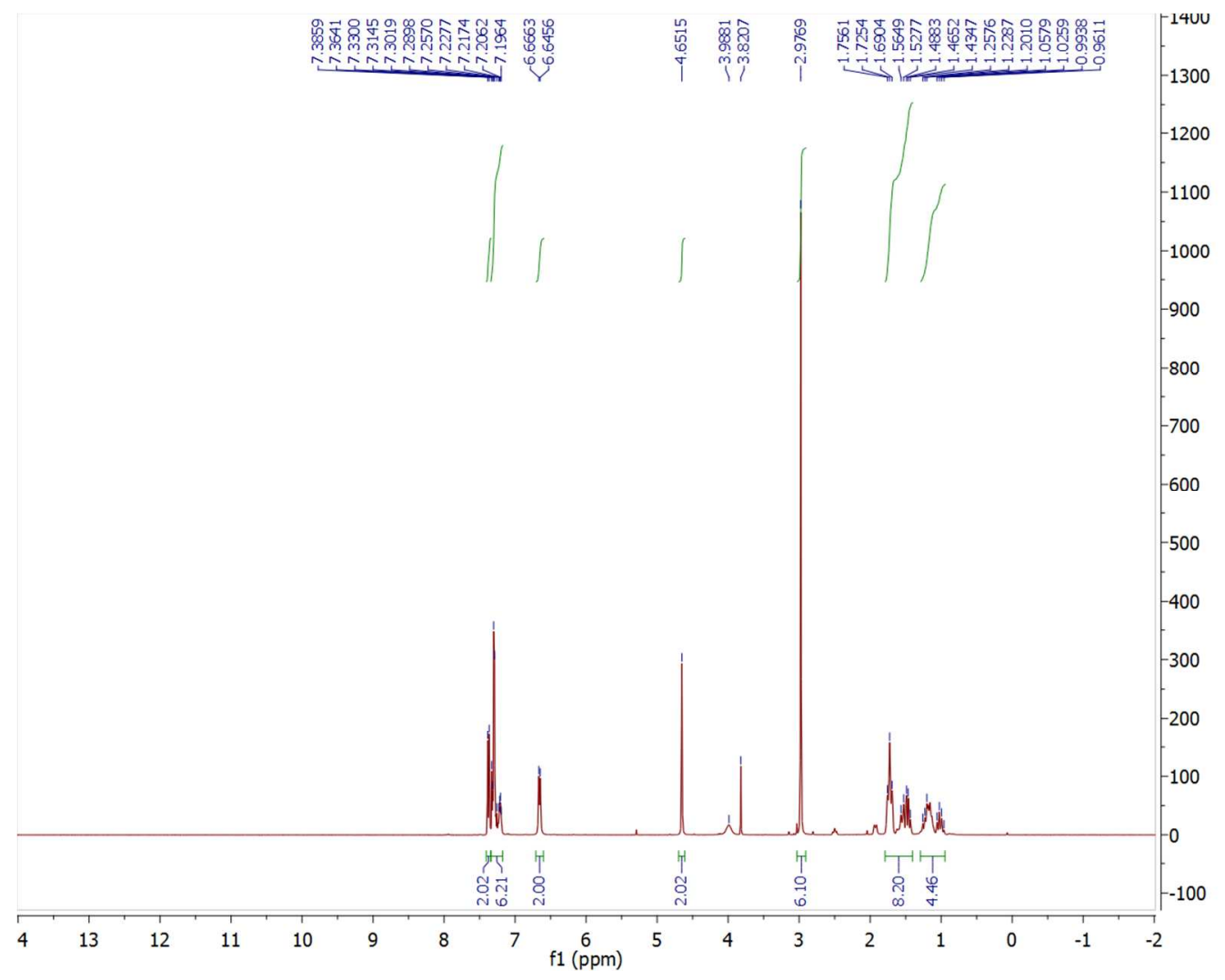




\section{${ }^{13} \mathrm{C}-\mathrm{NMR}$ of (S1)}

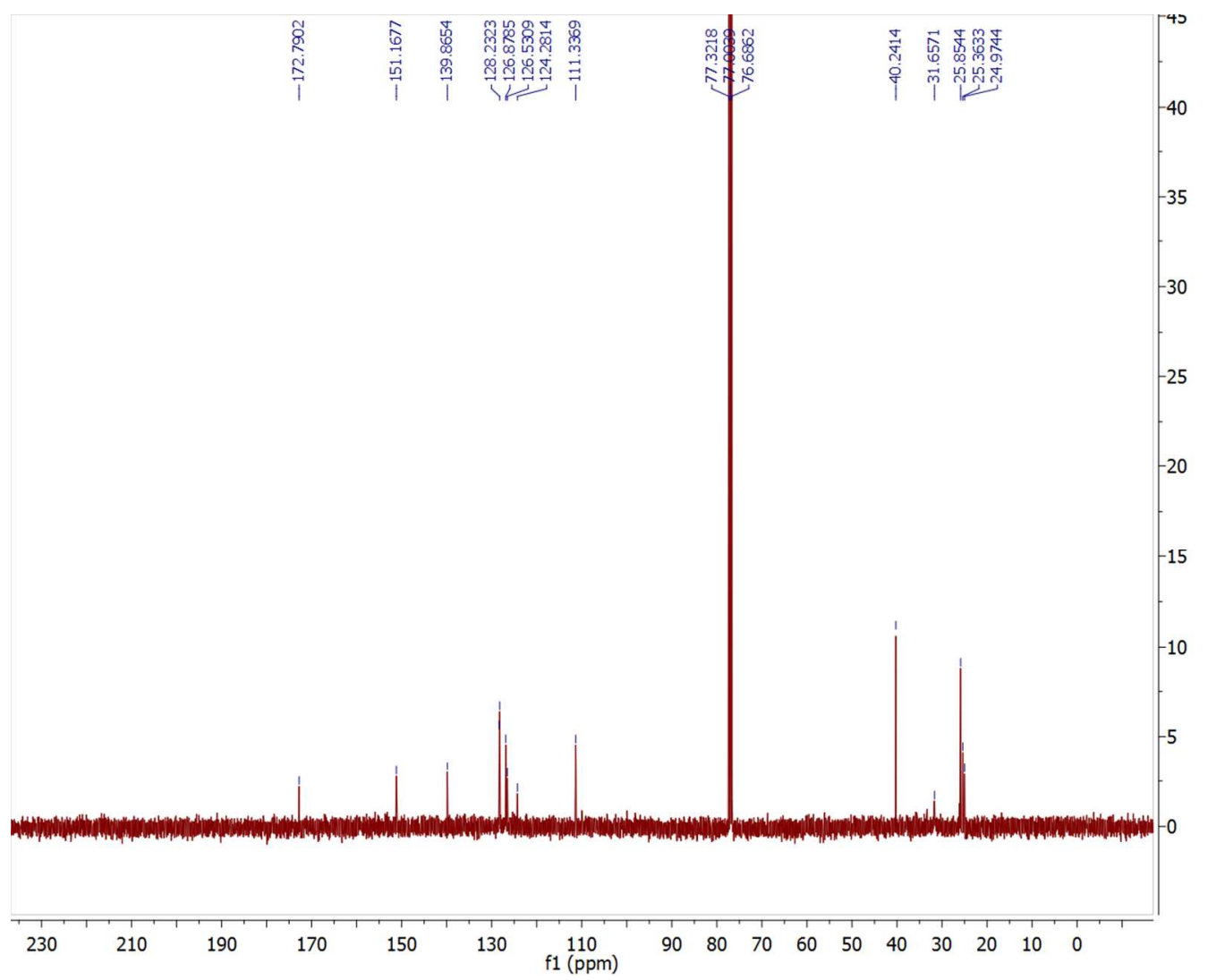

\section{HRMS of (S1)}

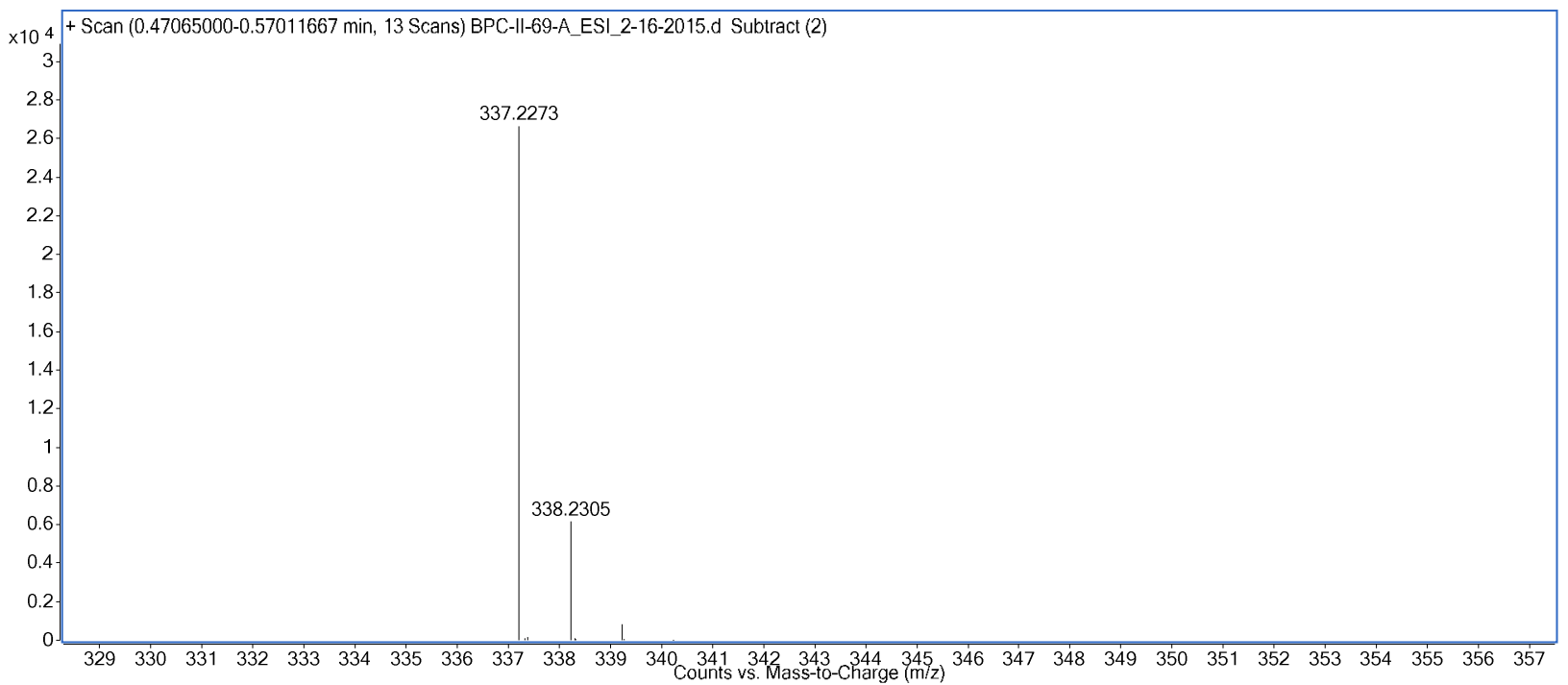




\section{Radiochemistry}

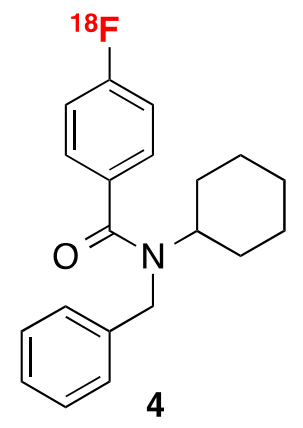

Synthesis of $\left[{ }^{18}\right.$ F]RAGER (4): see main manuscript.

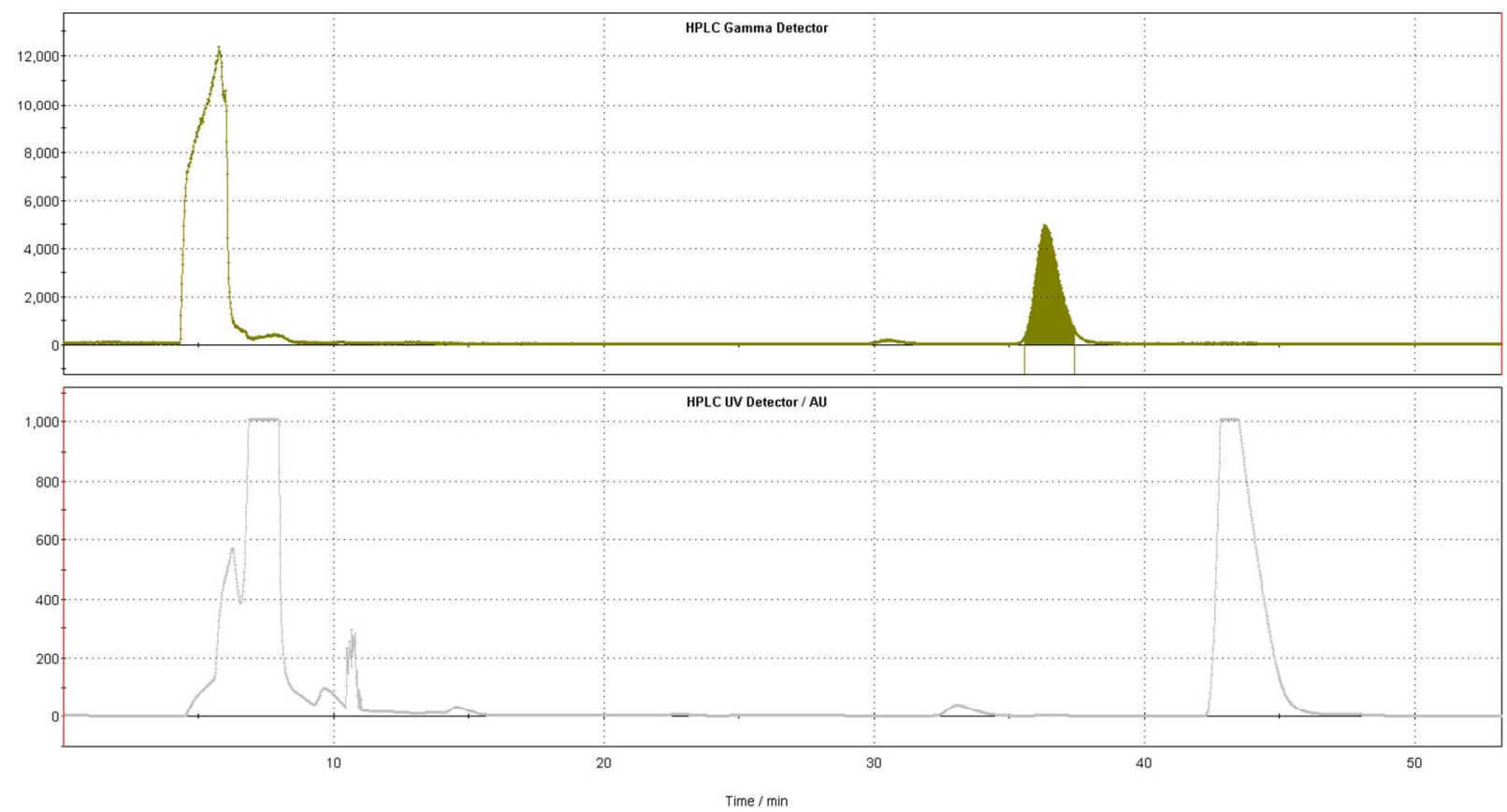

Figure S1: Representative semi-preparative HPLC trace for purification of $\left[{ }^{18} \mathrm{~F}\right] \mathrm{RAGER}$ 
Quality control of $\left[{ }^{18} \mathbf{F}\right]$ RAGER: Radiochemical purity of $\left[{ }^{18} \mathrm{~F}\right]$ RAGER was assessed using Shimadzu LC-2010A HT system equipped with the UV and RAD detectors (column: Phenomenex Gemini C18, 250x4.6 mm; mobile phase: $10 \mathrm{mM} \mathrm{NH}_{4} \mathrm{HCO}_{3}$ in $58 \% \mathrm{MeCN}, \mathrm{pH} 9$ adjusted with $2 \mathrm{~mL} / \mathrm{L}$ sat. $\mathrm{NH}_{4} \mathrm{OH}$ solution; flow rate: $1.0 \mathrm{~mL} / \mathrm{min}$; wavelength: $254 \mathrm{~nm}$; room temperature; product peak: $22.5 \mathrm{~min}$; see Figure S2 for a representative HPLC trace).

UV

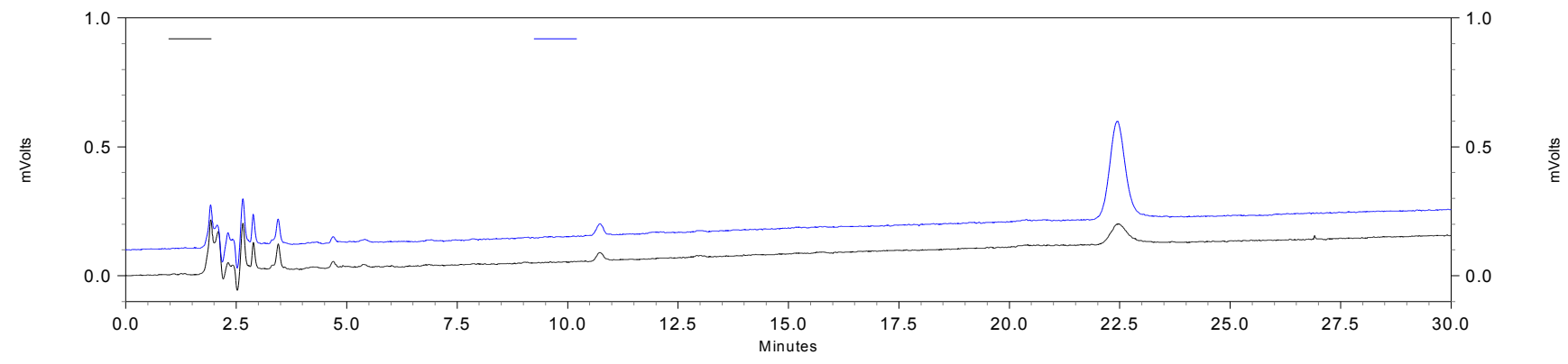

RAD

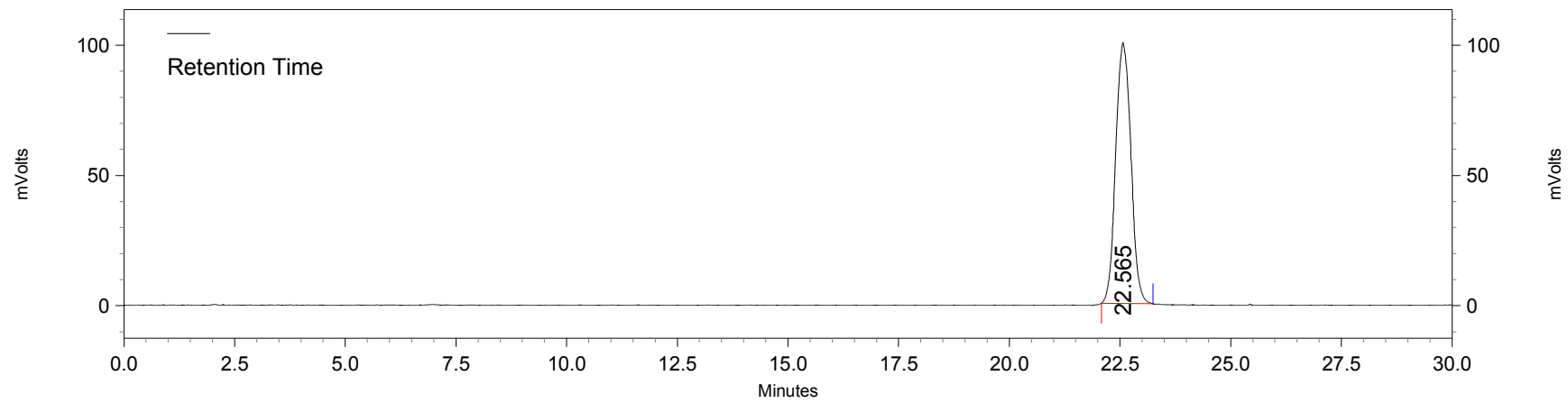

\begin{tabular}{|c|c|c|c|c|c|}
\hline $\begin{array}{c}\text { UV Detector } \\
\text { Ch1-254nm } \\
\text { Results }\end{array}$ & & & & & \\
\hline $\begin{array}{c}\text { Retention } \\
\text { Time }\end{array}$ & Area & Area \% & Height & Width & $\begin{array}{c}\text { S/N } \\
\text { (ASTM) }\end{array}$ \\
\hline 22.458 & 1967 & 100 & 76 & 1.075 & 3.67 \\
\hline
\end{tabular}

\begin{tabular}{|c|c|c|c|}
\hline RAD Results & & & \\
\hline Retention Time & Area & Area $\%$ & Width \\
\hline 22.565 & 2383856 & 100 & 1.17 \\
\hline
\end{tabular}

Figure S2: Representative analytical HPLC trace of $\left[{ }^{18} \mathrm{~F}\right]$ RAGER (black traces) and coinjection with unlabeled reference standard (blue trace; offset $=+0.1 \mathrm{mV}$ ) 


\section{Immunohistochemistry}

Brains blocks were received from the Michigan Alzheimer's Disease Center Brain Bank and 20 $\mu \mathrm{m}$ thick sections were cut on a Hacker cryostat. Sections were post-fixed in Davidson's Fixative then rinsed with many changes of $70 \%$ ethanol. Antigen retrieval was accomplished with $1 \%$ SDS in PBS buffer then slides were quenched in $0.3 \% \mathrm{H}_{2} \mathrm{O}_{2} / 70 \% \mathrm{MeOH}$ and blocked with PBSTBA (Phosphate Buffered Saline pH 7.4, 0.4\% Triton X-100, 1\% BSA, 0.025\% $\mathrm{NaN}_{3}$ ). Sections were incubated for $16-20 \mathrm{~h}$ at $4{ }^{\circ} \mathrm{C}$ in a 1:1000 dilution of rabbit anti-human RAGE 1 (residues near caboxy terminus) antibody (Life Technologies, MD, USA). Sections were then incubated with a biotinylated goat anti-rabbit antibody (Vectastain, Vector Laboratories, CA, USA) for 30 min and $\mathrm{ABC}$ Reagent for 30 min at room temperature and then antibody binding was visualized by formation of the avidin-biotin-peroxidase complex and addition of the chromogen DAB. Sections were counter-stained with Giemsa. RAGE-positive cells were quantitated using a Leica DMR microscope attached to a computer running StereoInvestigator (Microbrightfield, Inc., VT, USA). A representative image of a brain tissue section from an Alzheimer's disease patient is shown in Figure S3.

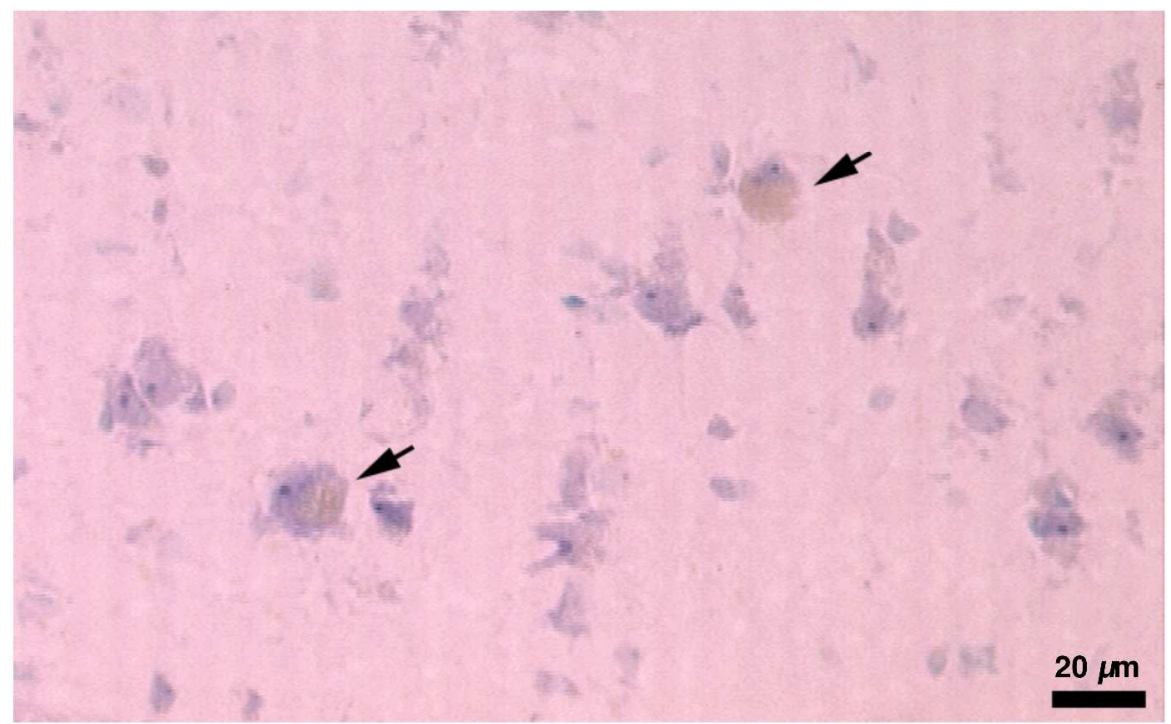

Figure S3: RAGE immunohistochemistry in frontal cortex tissue sample from Alzheimer's disease patient (arrows show RAGE immunopositive cells) 


\section{Autoradiography}

\section{Preparation of tissue sections}

Frozen blocks ( 1 x 1 inch) from the postmortem brain (frontal cortex) of Alzheimer's disease patients $(n=2)$ and normal controls $(n=2)$ were used for the autoradiography experiments. Tissue was obtained from the University of Michigan Alzheimer's Disease Center Brain Bank. Frozen blocks were sliced into $20 \mu \mathrm{m}$ sections using a Hacker Instruments cryostat set to $-15^{\circ} \mathrm{C}$. Sections were mounted on $1 \times 3$ inch polylysine-coated glass slides and stored at $-80{ }^{\circ} \mathrm{C}$.

\section{Quantitative autoradiography procedure}

Brain sections were removed from $-80^{\circ} \mathrm{C}$ freezer and thawed at room temperature for $5 \mathrm{~min}$ before rehydration in phosphate buffer saline (PBS) - ethylenediaminetetraacetic acid (EDTA) $\mathrm{pH} 7.4$ for another $5 \mathrm{~min}$. Then, brain sections were incubated in various concentrations $(0.5-200$ $\mathrm{nM})$ of $\left[{ }^{18} \mathrm{~F}\right] \mathrm{RAGER}$ in PBS-EDTA $\mathrm{pH} 7.4$ for $30 \mathrm{~min}$ to determine total binding. Nonspecific binding was determined by incubating the adjacent brain sections for $30 \mathrm{~min}$ using the same $\left[{ }^{18} \mathrm{~F}\right]$ RAGER concentrations and in the presence of $10 \mu \mathrm{M}$ of cold RAGER. All sections were washed twice in PBS-EDTA $\mathrm{pH} 7.4$ for $2 \mathrm{~min}$ and then rinsed in $\mathrm{dH}_{2} \mathrm{O}$ briefly to remove unbound radioactivity. Calibration standards were prepared by spotting $5 \mu \mathrm{L}$ of various $\left[{ }^{18} \mathrm{~F}\right]$ RAGER concentrations onto a TLC plate. Finally, slides and the TLC plate were dried under the continuous airflow for $5 \mathrm{~min}$ before exposing them simultaneously to high-resolution phosphoimaging plate for $15 \mathrm{~min}$. The exposed plate was scanned using Typhoon 7000 phosphoimager. Image analysis was performed using ImageQuant (Molecular Dynamics) software. $\mathrm{K}_{\mathrm{d}}$ and $\mathrm{B}_{\max }$ were calculated using non-linear regression analysis (GraphPad Prism software version 6.0b).

\section{LogP Determination}

Reference standard 2 (1 mg) was dissolved in a 1:1 mixture of 1-octanol and water $(2 \mathrm{~mL})$. The resulting mixture was vortexed for $5 \mathrm{~min}$, and then allowed to settle for $30 \mathrm{~min}$. $100 \mu \mathrm{L}$ samples were carefully removed from each layer and analyzed by HPLC. The area under the curve for each was taken, and used to calculate a $\log \mathrm{P}_{\text {oct/water }}$ of 3.5 . 


\section{Rodent and Primate MicroPET}

General considerations: All animal studies were performed in accordance with the standards set by the University Committee on Use and Care of Animals (UCUCA) at the University of Michigan.

Primate imaging studies: Imaging was done using a mature female rhesus monkey $(\mathrm{n}=1$, weight $=8.4 \mathrm{~kg}$ ). The monkey was anesthetized (isoflurane), intubated, and positioned in a Concorde MicroPET P4 scanner. Following a transmission scan, the animal was injected i.v. with $\left[{ }^{18} \mathrm{~F}\right]$ RAGER $(4.8 \mathrm{mCi})$ as a bolus over $1 \mathrm{~min}$, and the brain imaged for $90 \mathrm{~min}(5 \mathrm{x} 1 \mathrm{~min}$ frames $-2 \times 2.5$ min frames $-2 \times 5$ min frames $-7 \times 10$ min frames).

Rodent imaging studies: Studies were done using male Sprague Dawley rats $(\mathrm{n}=3$, weights $=$ $257-303 \mathrm{~g}$ ). The animals was anesthetized (isoflurane), intubated, and positioned in a Concorde MicroPET P4 scanner. Following a transmission scan, the animals were injected i.v. (via intravenous tail vein injection) with $\left[{ }^{18} \mathrm{~F}\right]$ RAGER $(0.456-0.560 \mathrm{mCi})$ as a bolus over $1 \mathrm{~min}$, and the brain imaged for $90 \min (5 \times 1$ min frames $-2 \times 2.5$ min frames $-2 \times 5$ min frames $-7 \times 10$ min frames).

Image analysis: Emission data were corrected for attenuation and scatter, and reconstructed using the 3D maximum a priori method (3D MAP algorithm). Using a summed image of the entire data set, regions of interest (ROIs) were drawn manually on multiple planes to obtain volumetric ROIs for the whole brain (rodent) or whole brain, striatum, thalamus, cortex, hippocampus and cerebellum (primate). The volumetric ROIs were then applied to the full dynamic data sets to obtain the regional tissue time-radioactivity data. 


\section{Molecular Docking}

The NMR model of the human vRAGE $23-121-\mathrm{S} 100 \mathrm{P}$ interaction was retrieved from the Protein Database (PDB) with the PDBID: $2 \mathrm{MJW}^{1}$ (Model 1). The interface(A) residues (A21, P46, Q47, R48, E50, K52, L53, N54, R57, T58, W61, K62,V63, L64, S65, P66, Q67, G68, G69, G70, P71, R98, Q100, R104, E108, K110, N112) on RAGE were determined with the InterfaceResidues.py script (Jason Vertrees, 2009) using default cutoff $\left(1 \AA^{2}\right)$. Using these parameters, the search space for the high resolution crystal structure (PDB:3O3 $\mathrm{U}^{2}$ ) was defined encompassing the RAGE-S100P interface (center_ $\mathrm{x}=57.46$, center_y $=31.705$, center_z $=60.443$, size_ $\mathrm{x}=70$, size $\_y=54$, size $\_z=78$ ). Docking was performed with Autodock Vina 1.1.2. ${ }^{3}$ Default parameters were used with the exception of exhaustiveness increased to a value of 30 . Resulting poses were inspected and the lowest energy pose was selected. Images were rendered in PyMOL or AutoDock (Figure S4B) tools.

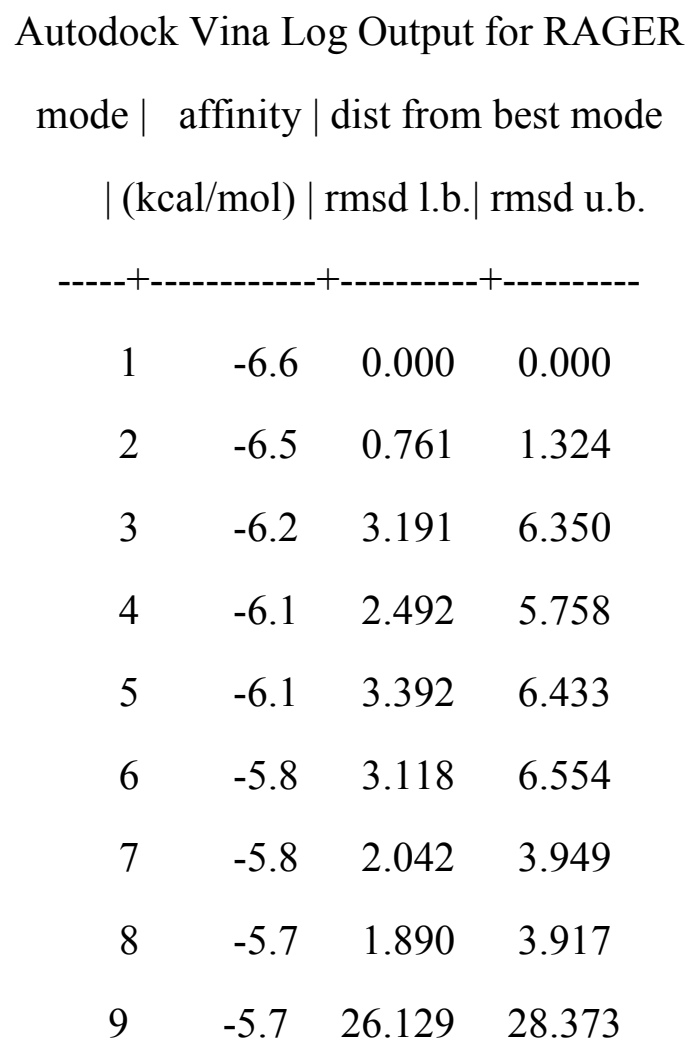

Table S1: Autodock Vina Log Output for RAGER 


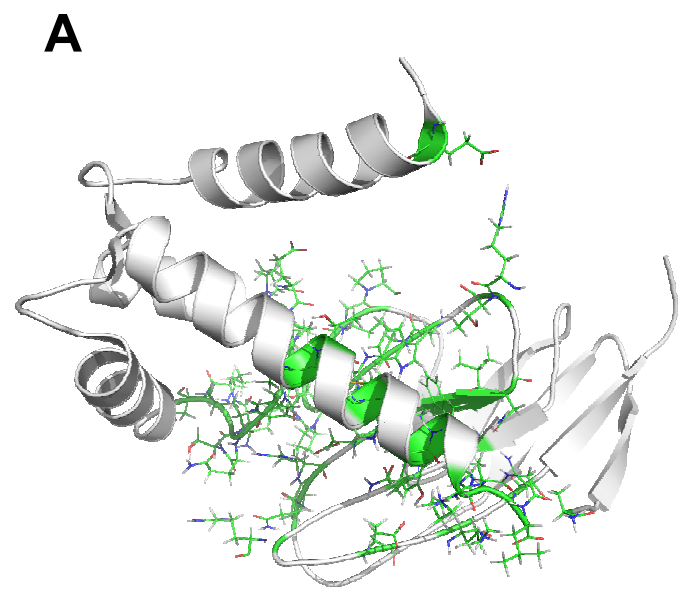

C
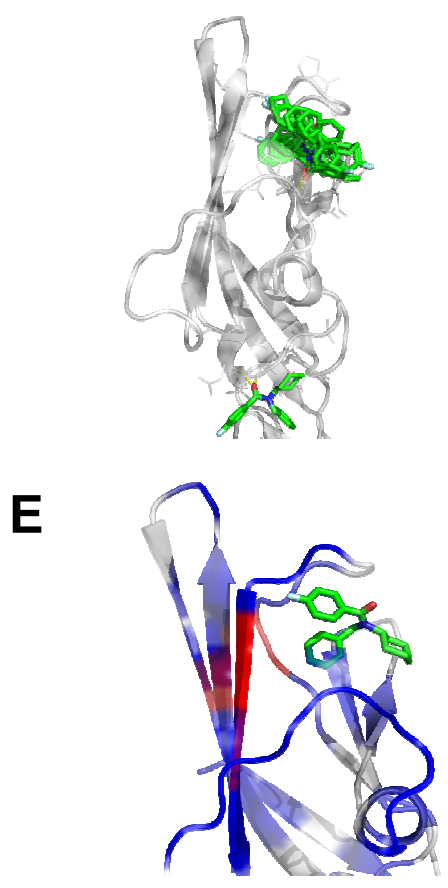

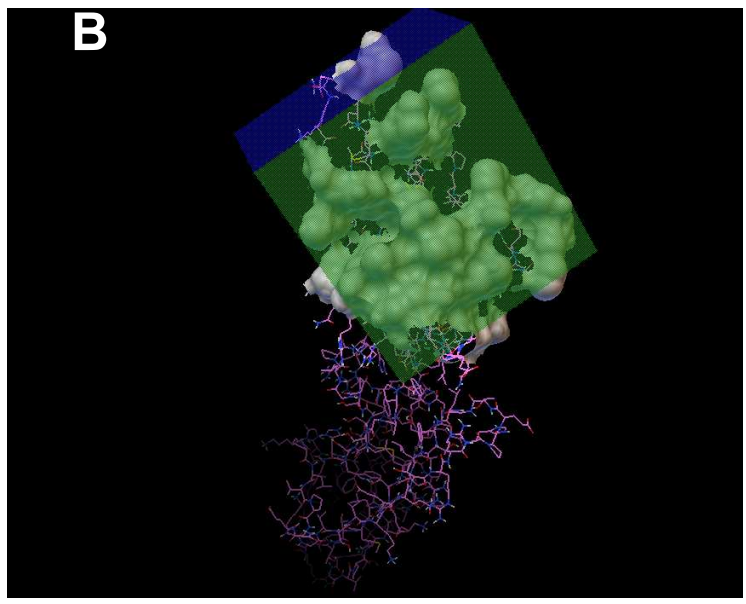

D

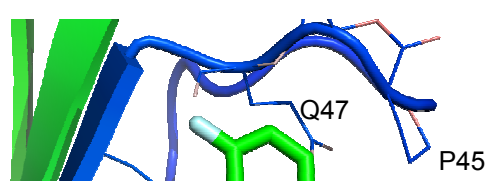

L49
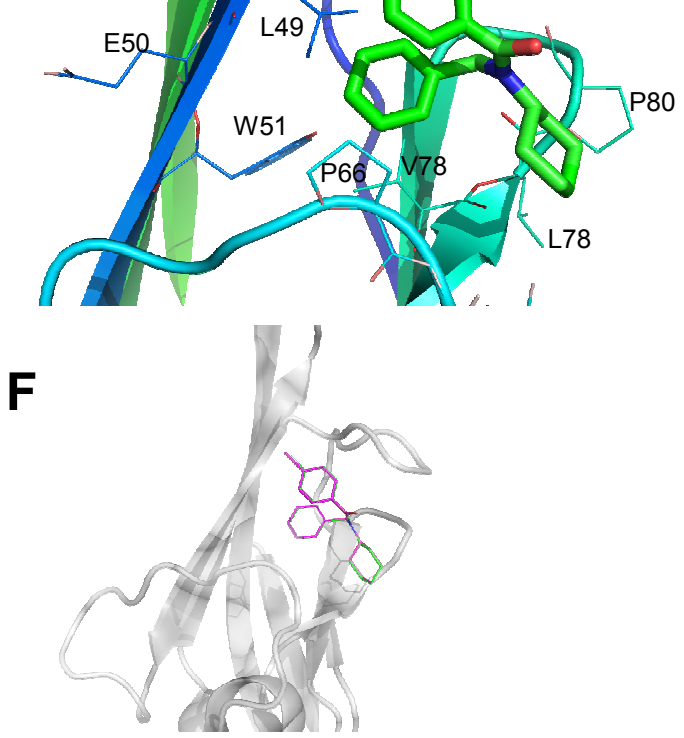

Figure S4: Molecular docking rendered with PyMOL and Autodock Tools (B only): (A) S100PvRAGE complex (PDB: 2MJW, Model 1) with interface residues colored green and displayed as sticks; (B) $1.5 \AA$ crystal structure of RAGE (PDB: 3O3U) with interface residues shown as surface representation. Box indicates Autodock Vina search space; (C) Ensemble of docked RAGER-RAGE poses; (D) Close-up of lowest-energy docked pose with residues in close proximity labeled; (E) Lowest energy RAGER-RAGE docking pose with S100P interface residues highlighted in blue and $\beta 3$ strand of importance to RAGE-A $\beta$ interaction highlighted red; (F) RAGER lowest-energy docking pose (carbon atoms colored green) overlaid with FPSZM1 lowest-energy pose docked with same parameters. 
VIII: Liver Microsome Metabolism Study

\section{Metabolic Stability Report \\ Metabolic Stability of Compound RAGER in Rat Liver Microsomes}

\section{Results}

Metabolic Stability

The metabolic stability and $\mathrm{T}_{1 / 2}$ of test compound and verapamil as positive control in rat liver microsomes with NADPH are listed in the Table S2, and plotted in Figure S5.

\begin{tabular}{|c|c|c|}
\hline \multirow{2}{*}{ Time point (min) } & \multicolumn{2}{|c|}{ Percentage remaining (\%) } \\
\cline { 2 - 3 } & Rage & 100 \\
\hline 0 & 100 & 10.70 \\
\hline 5 & 0.53 & 3.35 \\
\hline 10 & 0.73 & 1.45 \\
\hline 15 & 0.76 & 0.19 \\
\hline 30 & 0.60 & 0.087 \\
\hline 45 & 0.76 & 0.032 \\
\hline 60 & 0.47 & 1.55 \\
\hline Half life (min) & 0.66 & \\
\hline
\end{tabular}

Table S2. Metabolic Stability and Half Life in Rat Microsomes 


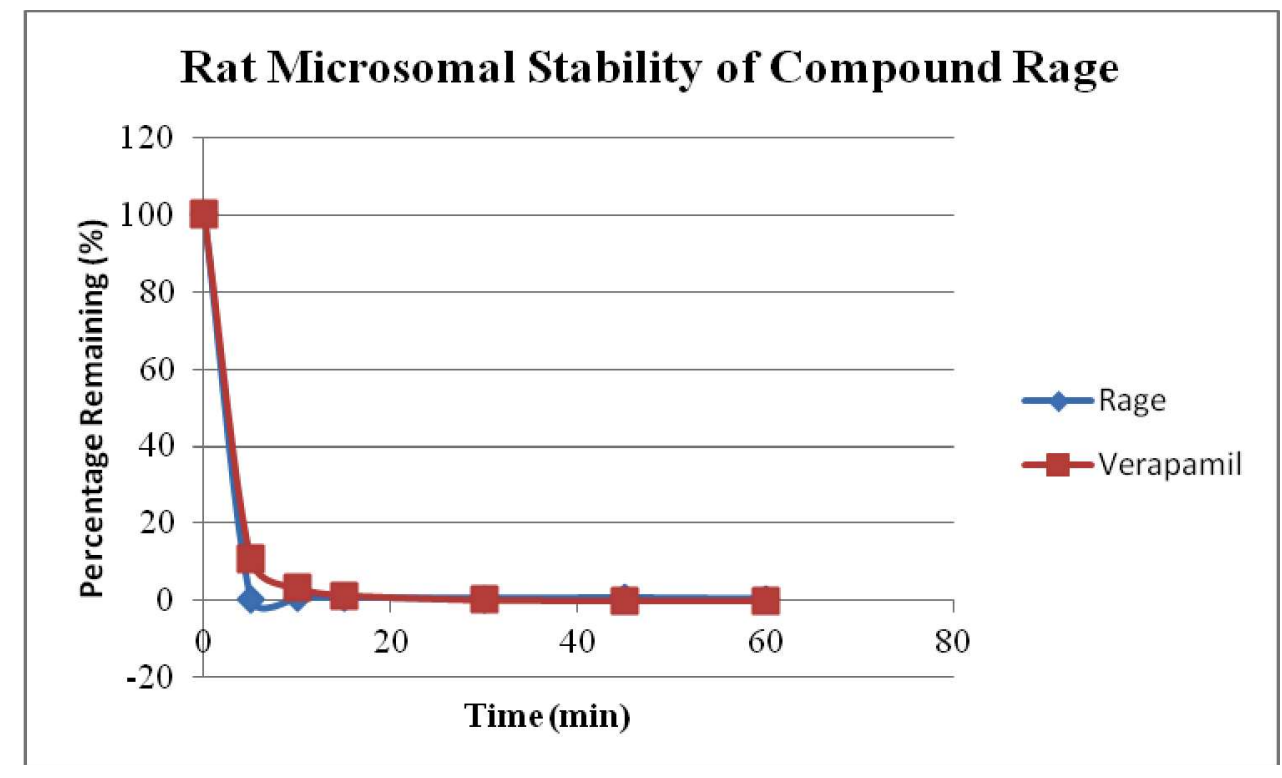

Figure S5. Metabolic Stability in Rat Liver microsomes with NADPH

\section{Materials}

\section{Materials and Methods}

Pooled rat microsomes were stored at $-80{ }^{\circ} \mathrm{C}$ prior to use.

\section{Study design}

The microsome incubation system was prepared according to the Table S3.

1. Make a master-mix containing microsome, phosphate buffer and NADPH solution as follows:

1) Dilute $10 \mu \mathrm{L}$ of microsome $(20 \mathrm{mg} / \mathrm{mL})$ with $330 \mu \mathrm{L} 0.1 \mathrm{M}$ Phosphate buffer $(3.3 \mathrm{mM}$ $\mathrm{MgCl}_{2}$ );

2) Dissolve about $1 \mathrm{mg}$ of NADPH in $60 \mu \mathrm{L}$ of $0.1 \mathrm{M}$ phosphate buffer $(3.3 \mathrm{mM}$ $\mathrm{MgCl}_{2}$ );

3) Addition of $40 \mu \mathrm{L}$ of $10 \mu \mathrm{M}$ test compound to microsome;

4) Pre-warm the master solution in the $37^{\circ} \mathrm{C}$ for $3 \mathrm{~min}$.

2. Add $20 \mu \mathrm{L}$ NADPH to the above master solution to initiate the reaction according to the Table S3. The final concentration of test compound in the reaction system is $1 \mu \mathrm{M}$.

\begin{tabular}{|l|c|c|c|c|}
\hline & $\begin{array}{c}\text { Master } \\
\text { solution }\end{array}$ & $\begin{array}{c}\text { Stock } \\
\text { concnetration }\end{array}$ & Volume & Sampling time (min) \\
\hline Test compounds & $380 \mu \mathrm{L}$ & $10 \mu \mathrm{M}$ & $40 \mu \mathrm{L}$ & $0,5,10,15,30,45$ and 60 \\
\hline
\end{tabular}

\section{Table S3. Microsome Incubation System}

3. Aliquot of $40 \mu \mathrm{L}$ was pipetted from the reaction solution and stopped by the addition of 4 volume of cold acetonitrile containing $50 \mathrm{nM}$ of CE105 as an internal standard at the designated time points. The incubation solution was centrifuged at $3500 \mathrm{~g}$ for 10 minutes to precipitate protein. The supernatant was used for $\mathrm{LC} / \mathrm{MS} / \mathrm{MS}$ analysis. 


\section{Data Analysis}

The natural log peak area ratio (compound peak area/ internal standard peak area) was plotted against time and the gradient of the line determined.

\section{LC-MS/MS Conditions}

Chromatographic Conditions:

Column : $5 \mathrm{~cm}$ x $2.1 \mathrm{~mm}$ I.D., packed with $3.5 \mu \mathrm{m}$ XBridge (Waters)

Mobile Phase A: $0.1 \%$ formic acid in purified deionized water

Mobile Phase B: $0.1 \%$ formic acid in acetonitrile

Flow Rate: $0.4 \mathrm{~mL} / \mathrm{min}$; Injection Volume: $5 \mu \mathrm{L}$

Run Time: $6.1 \mathrm{~min}$

$$
\text { Gradient Program: }
$$

\begin{tabular}{ccc}
\hline Time $(\min )$ & $\% \mathrm{~A}$ & $\% \mathrm{~B}$ \\
\hline 0.1 & 95 & 5 \\
0.5 & 95 & 5 \\
1.5 & 5 & 95 \\
3 & 5 & 95 \\
3.1 & 95 & 5 \\
6.0 & 95 & 5 \\
6.1 & stop & \\
\hline
\end{tabular}

\section{MS/MS Conditions}

Turbo-Ionspray ${ }^{\mathrm{TM}}$ Interface used in the positive ion-mode MRM-transitions:

\begin{tabular}{ccccccc}
\hline Compound & $\begin{array}{c}\text { Q1 } \\
\text { Mass } \\
(\mathrm{m} / \mathrm{z})\end{array}$ & $\begin{array}{c}\text { Q3 } \\
\text { Mass } \\
(\mathrm{m} / \mathrm{z})\end{array}$ & DP & EP & CE & CXP \\
\hline Rage & 312.2 & $\begin{array}{c}230.2 \\
122.9\end{array}$ & 100 & 8 & $\begin{array}{c}24 ; \\
30\end{array}$ & 10 \\
Verapamil & 455.2 & 303.2 & 110 & 9 & 34 & 14 \\
\hline
\end{tabular}




\section{IX: References}

(1) Penumutchu, S. R., Chou, R.-H., and Yu, C. (2014) Structural Insights into Calcium-Bound S100P and the V Domain of the RAGE Complex. PLoS ONE, 9, Article e103947.

(2) Park, H., and Boyington, J. C. (2010) The 1.5 A Crystal Structure of Human Receptor for Advanced Glycation Endproducts (RAGE) Ectodomains Reveals Unique Features Determining Ligand Binding. J. Biol. Chem. 285, 40762-40770.

(3) Trott, O., and Olson, A. J. (2010) AutoDock Vina: Improving the speed and accuracy of docking with a new scoring function, efficient optimization, and multithreading. J. Comput. Chem. 31, 455-61. 